\title{
EL PAISAJE, SU PATRIMONIALIZACIÓN Y EL BENEFICIO ECONÓMICO
}

\author{
Manuel Corbera Millán \\ Departamento de Geografía, Urbanismo y Ordenación del Territorio. Universidad de Cantabria \\ manuel.corbera@unican.es
}

\section{RESUMEN}

Desde hace dos décadas se viene asistiendo a un renovado interés por el paisaje en distintas disciplinas e instituciones políticas y administrativas. Algunos autores lo interpretan desde una perspectiva neorromántica, como reacción a los efectos destructores de la modernidad. El Convenio Europeo del Paisaje (CEP) estableció en Florencia en el año 2000 una definición de paisaje ampliamente aceptada y unas pautas de intervención sobre el mismo que pretenden ser el marco para las leyes nacionales y regionales de los países firmantes. El presente trabajo se propone explicar la recuperación del interés por el paisaje desde la perspectiva de la valorización económica del territorio, como externalidad que permite generar rentas. En mi opinión esa es la verdadera orientación de la CEP.

Palabras clave: paisaje; cultura; patrimonio; política; ordenación del territorio.

\section{ABSTRACT}

\section{The landscape, its heritage status and economic benefit}

The last two decades have seen a renewed interest in the landscape by different scientific areas and political and administrative institutions. This has been interpreted by some authors from a neo-romantic perspective, considering it as a reaction to the destructive effects of modernity. The European Landscape Convention (ELC), which was signed in Florence in the year 2000, established a widely accepted definition of landscape and intervention guidelines that aim to create the framework of national and regional laws of the signatory countries. This paper aims to explain the revival of interest in the landscape from the point of view of the economic development of the area, as an externality that generates revenue. In my opinion that is the real orientation of the ELC.

Key words: landscape; culture; heritage; politics; spatial planning.

\section{INTRODUCCIÓN}

El retorno del interés por el paisaje desde hace ya dos décadas, y de forma más intensa durante la última, no ha sido cosa solamente de la Geografía. Disciplinas tan diversas como la Ecología, la Historia, el Arte, la Estética (vinculada sobre todo a la arquitectura y la ingeniería) e incluso la Economía, vienen reflexionando sobre esa noción o simplemente utilizando el término en sus respectivos discursos. Esta múltiple mirada está contribuyendo a desvelar su amplia polisemia, que para algunos es precisamente el resultado de la propia diversidad disciplinaria (Besse, 2006). Esta constatación, bien fundamentada en la realidad, no explica sin embargo por qué el paisaje reaparece con esta capacidad de atracción; qué lo hace hoy tan interesante para todas esas disciplinas, algunas de las cuales (como la Economía) nunca lo habían estudiado con anterioridad.

Por otra parte, la polisemia del término no resulta tan variada como aparenta. Simplificando podríamos reunir todos esos significados aparentemente distintos en dos: uno objetivo, que lo define como fisonomía de la realidad física del espacio geográfico, y otro que pone el acento en la percepción sensible y 
emotiva, incluyendo aquí, por supuesto -aunque no sólo-, la representación artística. En ambos casos se trata de representaciones. No existe un paisaje material. La realidad representada es el espacio geográfico, pero la aproximación a dicho espacio puede realizarse desde la observación de su fisonomía, reveladora de las relaciones (espacio-temporales) entre sus elementos, o desde la contemplación sensible o emocional. Esta última se encuentra, sin duda, mucho más cercana a la representación pictórica o literaria, y -en palabras de Peter Burke (2005) - es más bien una imagen de una imagen. La primera lo está de la representación objetiva, aunque no deja de ser una reducción selectiva de la realidad.

En la recuperación actual del paisaje viene siendo habitual que buena parte de los autores de las disciplinas mencionadas (a excepción quizás de la Historia), no sólo no deslinden ambos significados, sino que los consideren íntimamente interrelacionados, asegurando que ninguno de los dos puede faltar. El primero sería la base del segundo, pero sin el segundo no hay paisaje: si no existe una mirada sensible sólo se podría hablar de territorio, de espacio, quizás de país, pero nunca de paisaje. En realidad, en ese cruce de miradas - principalmente entre la estética y la geografía- parece haberse producido un reconocimiento mutuo de las partes semánticas del concepto que cada disciplina tenía menos en cuenta: la estética refuerza la vertiente física del paisaje, la geografía su vertiente emocional. Ya hay quienes hablan de un enfoque de síntesis (Oueslati, 2011), un enfoque que parece adaptarse bien a la propia definición que del término proporcionó el Convenio Europeo del Paisaje.

En cualquier caso no hemos de olvidar que el concepto de paisaje -como cualquier otro- no es más que una construcción intelectual, un artefacto, una puerta de conocimiento, un objeto de estudio, un instrumento para la intervención política o para la especulación económica. De ahí que en parte su polisemia, más que deberse a las diferentes aproximaciones disciplinares, está relacionada con la utilidad que se le da. De hecho ha sido redefinido muchas veces a lo largo de su historia en función del papel que se le asignaba, es decir, de para qué servía. No se equivocaba Yves Lacoste cuando allá por el año 1977 se cuestionaba precisamente esto para aclarar qué era el paisaje. Las preguntas que se plantea este artículo son, por tanto, por qué se produce en las últimas décadas la recuperación del paisaje, por qué bajo esa conceptualización de síntesis y para qué sirve el paisaje hoy.

\section{EL NACIMIENTO DE LA NOCIÓN DE PAISAJE ENTRE LA FILOSOFÍA Y EL ARTE}

Como es bien sabido, el paisaje es una noción cultural no estrictamente -ni siquiera primigeniamente-geográfica. Especialistas como Berque (geógrafo y filósofo orientalista) o Maderuelo (arquitecto y especialista en estética) llevan ya tiempo rastreando sus orígenes. Ambos autores parten de la consideración de que tal noción se forma solamente cuando en una sociedad se alcanza un estadio que permite la mirada contemplativa y la valoración estética. En Occidente, y más particularmente en Europa, no se reconoce hasta el Renacimiento (Berque, 2009), de la mano del Humanismo, y se difunde principalmente desde la pintura. De ahí le viene su connotación estética y también su asociación a una sensibilidad contemplativa.

El paisaje fue surgiendo -podríamos decir que emancipándose- desde los fondos de las pinturas, desde los lejos que servían para dar profundidad a los cuadros. En sus inicios, esos fondos de los cuadros de Giotto y de buena parte de la pintura tardomedieval y del primer Renacimiento, aparecen como escenarios ideales formados por elementos tópicos: colinas, árboles, castillos y ciudades. Poco a poco, en algunas pinturas, particularmente en las italianas y las nórdicas, los paisajes fueron adquiriendo más importancia hasta envolver totalmente la escena e incluso llegar a eliminarla. Y poco a poco, también, los paisajes comenzaron a representar escenarios reconocibles, aunque no siempre fieles totalmente al modelo. En 1532 un cuadro de Albrecht Altdorfer representaba un lugar de los Alpes en el que ya no aparecía ninguna escena ni ningún ser humano (Gombrich, 1990). Desde entonces el paisaje como género pictórico propio fue adquiriendo cada vez más importancia, ayudando a conformar el gusto por la contemplación de la naturaleza y también la concepción de la belleza paisajística. Durante el siglo XVII fueron los pintores protestantes holandeses los que acabaron por consolidar la pintura de paisaje como género independiente. Pero fue, sin duda, Claudio de Lorena quién más contribuyó a imponer un canon de belleza paisajística a partir de su idealización de la campiña romana (Gambrich, 1990).

El paisaje artístico se consolidaría como género en el siglo XVIII. Algunos subgéneros alcanzaron en esa época gran difusión y fama, como el de las realistas "vedutas", bien representadas en las numerosas vistas de las ciudades más visitadas de Italia: las de Roma de Vanvitelli, por ejemplo, o las de Venecia de 
Canaletto y Gurdi. Vistas que los viajeros, sobre todo ingleses, se llevaban como recuerdo a su país, y que contribuían a animar a nuevos viajeros, es decir, que servían de reclamo turístico.

$\mathrm{Y}$ esos viajeros aprendieron desde la pintura a mirar y valorar el paisaje, entendido ahora no como mera representación pictórica, sino como vista del propio espacio, de la naturaleza, de la organización territorial. Aprendió a valorar las vistas "pintorescas", aquellas que se parecían a las pinturas de los paisajistas; porque, como ha señalado Besse (2006), la "pintura de paisajes nos ha enseñado a mirar el mundo, pero nos ha enseñado a verlo, precisamente, como un cuadro de paisaje" (p. 149).

De esas miradas de viajeros cultos, frecuentemente artistas y escritores, surgiría una literatura de viaje que contribuiría igualmente a difundir, a llamar la atención, a estimular la sensibilidad ante la belleza de la naturaleza, de la aparente armonía que reinaba en los campos; en definitiva, la sensibilidad ante el paisaje. Y así la percepción individual del paisaje -más propia de artistas- se fue transformando en percepción social. Desde esta perspectiva podemos hablar de paisaje cultural, entendiendo aquí por cultura la que determina en un momento dado el enfoque sensible del observador. Porque lo que se consideraba belleza paisajística cambió a lo largo de la historia, y particularmente durante los siglos en que se fue imponiendo la propia noción de paisaje. Para el viajero ilustrado la belleza se identificaba con lo útil, con la naturaleza domeñada y ornamentada, mientras la montaña era despreciada por estéril y salvaje. Una concepción que conservaba la tradición medieval del loci amoeni, aunque reinterpretada en el siglo XVIII desde los planteamientos agraristas de la Ilustración impulsores de un desarrollo económico y comercial (ampliación de la zona cultivada y mejora de la misma), perspectiva íntimamente relacionada con el imaginario que domina el Tableau économique de Quesnay y Mirabeau (Ortas, 1999)

No habría, sin embargo, que esperar mucho para que se desplegara la experiencia estética romántica de la Naturaleza, primigenia, sublime, pintoresca y por todo ello bella. Categorías que enlazan mucho mejor con la actual revalorización estética de la naturaleza (Marchán, 2006). Una concepción en la que los nuevos cánones de belleza se entrelazan con su propia esencia y el principio creador schelligiano de la Naturalphilosophie. Los pintores paisajistas de la época creían así poder captarla. Caspar David Friedrich (1774-1840) lo expresaba elocuentemente: "El pintor -decía- no debe pintar meramente lo que ve ante sí, sino también lo que ve en sí" ${ }^{\prime \prime}$. Schelling sólo les concedía a ellos el privilegio de acceder a lo absoluto en la naturaleza a través de la belleza, que es la idea que todo lo unifica. Así entendían los filósofos idealistas alemanes el holismo de la naturaleza y del paisaje, como unión íntima e indisoluble entre todos sus elementos, inalcanzable para la ciencia. Y así también la entendía Humboldt (Corbera, 2013).

\section{EL PAISAJE EN EL ASCENSO Y CONSOLIDACIÓN DE LA BURGUESÍA: ¿PARA QUÉ SERVÍA ENTONCES EL PAISAJE?}

No se puede poner en duda la correspondencia entre el ascenso social y económico de la burguesía y la emancipación del paisaje como género pictórico y literario. Relación de correspondencia y no causal, como se apresuraría a decir Arnold Hauser (1975). El paisaje, como manifestación artística, se incorpora plenamente a la ascendente cultura burguesa desplazando las pautas religiosas y nobiliarias medievales y desplegando su nueva concepción del mundo.

Comienza siendo una ventana hacia la libertad por la que escapar del opresivo ambiente religioso medieval. De ahí que en la pintura de paisaje adquiriese sobre todo importancia en los Países Bajos calvinistas que durante el siglo XVII -y de forma casi aislada en Europa- practicaba un arte plenamente burgués (Hauser, 1975). Ello tenía que ver con la prohibición de representar corporalmente a Dios y escenas de la vida sagrada, y con la recomendación -hecha por el propio Calvino- de que sólo debía pintarse aquello que podía presentarse ante la vista. Coincidía también con el gusto de los mercaderes holandeses, que vieron en las pinturas de paisaje magníficos motivos de decoración para sus casas (Maderuelo, 2005). En el resto de los países el paisaje seguía aún siendo un género menor y pocas veces plenamente emancipado. Habría que esperar al siglo siguiente, cuando la burguesía ya había conquistado el poder económico y la influencia política, para que -como parte del nuevo gusto artístico- llegase a convertirse en uno de los géneros más apreciados en la pintura. La animación del mercado - que no dejaba fuera la cultura, el arte o la literatura- facilitó su difusión entre la nueva clase hegemónica, permitiendo enlazar directamente a intelectuales y artistas, que actuaban ya como agentes libres que ofrecían sus obras en los diferentes mercados.

1 Declaraciones en la visita a una exposición (1830). Recogido en Arnaldo, 1994, pp. 94-98. 
Este gusto burgués por el paisaje encajaba bien con sus aspiraciones y prácticas. El aumento de la movilidad, de los viajes, de los deseos de conquista de nuevos escenarios, se veía estimulado por los paisajes pintados o descritos en la literatura. Ya vimos el papel que las "vedutas" jugaron como reclamo turístico. Muchos de los viajeros se propusieron de hecho describir sus viajes para animar a otros a descubrir los escenarios que habían visitado. Y de hecho lo consiguieron. El nuevo género literario, como el pictórico, tuvo un enorme éxito en el siglo XIX. El propio Humboldt citaba las descripciones pintorescas de las islas del Mar del Sur de su amigo George Forster y un cuadro de Hodges que representaban las orillas del Ganges, como los principales estímulos que le habían impulsado a visitar las regiones tropicales. Y entre sus particulares objetivos se encontraban de hecho el de alentar a los jóvenes (científicos y artistas) a descubrir esos paisajes (Corbera, 2013).

Abrir el mundo, animar a su conocimiento y a su conquista, he aquí una de las funciones que cumplía el paisaje como representación estética. Pero no era desde luego la única. El paisaje empezó también enseguida a jugar un papel importante en la ordenación del espacio burgués, tanto público como privado. Adoptó así una forma física de representación social con criterios distintos de los de la aristocracia. Yves Luginbühl (1989) sostiene que a finales del siglo XVIII se creó una auténtica ideología paisajística en Francia que asimilaba la armonía paisajística a la armonía social y al orden moral, y también lo útil a lo agradable y bello. Una ideología a cuya elaboración contribuyeron los creadores de jardines (principalmente J. M. Morel y R. L. de Girardin), los escritores y, de forma muy importante, la agronomía, concebida entonces como una ciencia global que integraba todas las dimensiones, económica, social, pero también estética. Esta visión del paisaje, elevada a la condición de verdad universal y eterna, impregnó los medios políticos de la Revolución Francesa y se introdujo en los proyectos de ordenación del espacio rural y sobre todo en la puesta en cultivo de las landas y marismas, en las operaciones de plantaciones, en la ornamentación de los caminos con arbolado. Todo ello defendido con criterios higiénicos, económicos, ecológicos, sociales y estéticos, que no fueron, sin embargo, entendidos por un campesinado sumido en la pobreza y que lo consideraba una perturbación de sus prácticas y de sus medios de subsistencia.

También en Inglaterra se produjo a finales del siglo XVIII ese paso de las representaciones artísticas del paisaje a la práctica social. La formación de las imágenes paisajísticas suponía una cierta descomposición del paisaje y la supresión u ocultación de algunos elementos, entre los que destacaba precisamente el agrícola. Imágenes, difundidas a través de proyectos de jardines, de ilustraciones (litografías) de libros, que influyeron en las prácticas sociales, en concreto en las intervenciones de los grandes propietarios ingleses, que tendieron a eliminar de sus tierras las manifestaciones agrícolas (divisiones parcelarias, setos, surcos, cultivos) para transformarlas en terrenos de ocio, paseo, y caza (Luginbühl, 1991). Ello suponía expulsar a los campesinos, lo cual, por supuesto, no respondía a motivos meramente estéticos y recreativos, sino que venían a reforzar el proceso que Marx denominó en "El Capital" (1979, T. III) acumulación originaria, consistente en lanzar al mercado de trabajo nueva mano de obra para atender las necesidades de la primera industrialización.

El paisaje resultó ser, además, un extraordinario instrumento identitario, que unido a la sensibilidad romántica y convenientemente manipulado se convirtió en pieza clave de los discursos nacionalistas de la burguesía. Porque en realidad esa fuerza identitaria no es una cualidad intrínseca del paisaje, no existe si no se la construye, si no se la asocia en el propio discurso. Es bien conocido el esfuerzo realizado en nuestro país por Giner de los Ríos y los miembros de la Institución Libre de Enseñanza durante los últimos años del siglo XIX, por identificar el paisaje castellano con el solar patrio ${ }^{2}$. Un esfuerzo al que también se unieron pintores como Carlos Haes y Aurelio Bruguete, escritores noventayochistas como Azorín, Unamuno o Machado, e incluso científicos como Macpherson, Hernández Pacheco o Casiano de Prado (Casado de Otaola, 2010). Y construir la imagen selectiva del solar patrio llevaba con frecuencia aparejado deconstruir otras que pudiesen hacerla sombra. Para ello Giner de los Ríos juega con el género, calificando de femenino a los paisajes de las tierras del norte, suaves, bellos, pero sin fuerza, que contrastan con la virilidad de los valles del Guadarrama (Giner, 1886, 219). En otros casos se recurre al tamaño. Como ha señalado Juaristi (citado por Morales, 2008), si en la representación del paisaje vasco que hacía en 1851 José María Goizueta en el prólogo a sus Leyendas Vascongadas, éste es descrito en términos gran-

2 "Suaviza, sin embargo, este contraste una nota fundamental de toda la región, que lo mismo abraza al paisaje de la montaña que el del llano. En ambos se revela una fuerza interior tan robusta, una grandeza tan severa, aun en sus sitios más pintorescos y risueños, una nobleza, una dignidad, un señorío, como los que se advierten en el Greco ó Velázquez, los dos pintores que mejor representan este carácter y modo de ser poético de la que pudiera llamarse espina dorsal de España." (Giner, 1886, 219, p. 92). 
dilocuentes y sublimes ("montañas como en Escocia, verdes colinas como en Irlanda, ríos de escarpadas orillas como en Alemania, costas sombrías e inhóspitas como en las Hébridas"), Baroja y principalmente Unamuno, se esforzaron, por el contrario, en deconstruir y empequeñecer ese paisaje nacional en favor del castellano: "En el paisaje vasco todo parece estar al alcance de la mano y hecho a la medida del hombre que lo habita y anima; es un paisaje doméstico, de hogar, en el que se ve más tierra que cielo; es un nido. Todo es pequeño; vallecitos entre montañas" (Casado de Otaola, 2010, p. 262-263).

\section{EL PAISAJE HOY: ¿QUÉ ES, PARA QUÉ SIRVE Y A QUIÉN SIRVE?}

Es evidente que buena parte de los servicios que prestaba el paisaje en aquellos tiempos a la burguesía carecen hoy de utilidad o se presentan de manera distinta, como en el caso del reclamo turístico o de la ordenación territorial. Pero ello no quiere decir que no siga sirviendo a sus intereses.

Bastantes autores han insistido en explicar la recuperación del interés por el paisaje como una especie de toma de conciencia ante el deterioro que éste viene sufriendo como consecuencia de los procesos de industrialización y de urbanización. Se trataría de una suerte de nostalgia (Nieto, 2008) que invade a la población urbana apresada en el asfalto y cemento. En definitiva, sería el resultado del renacimiento de un sentimiento romántico, como siempre un poco crítico con las consecuencias de la modernidad y el progreso. Todo ello habría venido favorecido por una mejora de las condiciones de vida, del nivel de consumo y de la cultura. Sin embargo, estas razones no responden, en mi opinión, más que parcialmente a uno de los aspectos de la cuestión, el de la sensibilidad, que, por otra parte, ha sido estimulada y uniformizada desde los medios de comunicación y la cultura audiovisual. En realidad han sido éstos los que han movilizado y conformado esa conciencia social. La cuestión es preguntarse por qué y en interés de quién. Por eso la explicación principal debe buscarse en otra parte, en el centro del propio sistema socioeconómico y de su evolución en las últimas décadas.

La crisis de los años setenta del siglo pasado puso de manifiesto un exceso de capacidad industrial a nivel internacional que pronto se reveló como crónico (Brenner, 2009). La falta de competitividad de la industria occidental condujo a un fuerte proceso de reconversión que llevó al cierre y desaparición de una gran cantidad de industrias y dejó ocioso una parte importante del capital, el cual buscó su salida en otros nichos de inversión que proporcionaran beneficios. Una parte nada despreciable de dicho excedente encontró su lugar en la inversión inmobiliaria, hasta el punto de suponer un fuerte salto de escala en el avance del proceso de urbanización mundial. Otro sector, igualmente atractivo a los inversores e íntimamente relacionado con el anterior, fue el turístico. En ambos casos el territorio adquiriría un papel fundamental y diferente del demandado por las actividades productivas (industria y agricultura) durante la etapa fordista. Exigía la producción de espacio nuevo para el capital (Harvey, 2012) o la reconversión y refuncionalización de antiguos espacios industriales y urbanos. En el primer caso tomaba la forma de urbanización, entendida no solamente en el sentido físico de ocupación inmobiliaria, sino en el que la entendía Lefebvre (1972), es decir, como su incorporación a la sociedad urbana capitalista, con sus sistemas de valores, sus gustos, su cultura, su ideología. En el segundo caso remodelaba formas urbanas obsoletas que habían quedado improductivas.

El vehículo que permitió avanzar en este proceso fue la facilidad del acceso al crédito proporcionado en un mercado financiero desregulado. Crédito barato y sin apenas exigencias del que participaron empresas constructoras y turísticas, e incluso los propios hogares que -deslumbrados por el efecto riqueza que producía el continuado incremento del valor de su pequeño patrimonio (por el aumento del precio de la vivienda)- pudieron, a partir del endeudamiento, ampliar considerablemente su capacidad de consumo. El proceso fue también favorecido -y de forma significativa- por la ayuda de las instituciones públicas a todas las escalas: en primer lugar la de los Estados y organizaciones supraestatales (como la UE), que pusieron en marcha políticas activas e inversiones, proporcionando infraestructuras y equipamientos que atraían al capital inmobiliario y que permitían incorporar nuevos espacios a actividades económicas lucrativas; pero también la de las instituciones regionales, comarcales y locales, en tanto que territorios que debían ser objeto de inversiones urbanísticas y turísticas.

La valorización de estos nuevos espacios no consistía sólo en dotarlos de buenos y rápidos accesos, de iluminación, agua, saneamiento, etc. Era necesario hacerlos atractivos y, en cierto modo, diferentes, singulares, para que pudieran afrontar la competencia del mercado. Y es en este contexto en el que debemos entender la recuperación del interés por el paisaje hoy, como una parte del patrimonio territorial 
que junto a otras (patrimonio ecológico, arqueológico, edificado, etnográfico, etc. -muchas de las cuales también son visibles en el paisaje) sirven para "producir espacio".

No se trata, por tanto, de una reacción hacia un crecimiento industrial degradador del medio y del paisaje, como han argumentado algunos autores (Facchini, 2011). No es la consecuencia de que el paisaje se acabe y tengamos nostalgia de él (Nieto, 2008). El redescubrimiento del paisaje del que hablamos se produce cuando la industria se está contrayendo; muchas grandes fábricas desaparecen y la industria que queda no exige en su mayor parte extensas instalaciones y se orienta hacia sectores que en sí afectan en menor medida al paisaje. En el medio urbano fue precisamente esa contracción y el abandono de instalaciones, equipamientos e infraestructuras, lo que abrió las puertas a una reconversión de esos espacios utilizando criterios paisajísticos revalorizadores del entorno, de las viviendas existentes y de las de nueva construcción. Intervenciones creadoras, además, de una nueva imagen de la ciudad atractiva al turismo. Pensemos, por ejemplo, en la transformación de ciudades como Baltimore tras el colapso de la actividad industrial en los años Ochenta del siglo pasado (Harvey, 2011), o del puerto de Brooklyn (New York) convertido en parque público en 2003 (Berrizbeitia, Hecht y Muñoz, 2008) o en la reconversión del entorno de la ría de Bilbao. Los ejemplos podrían ser miles, y en todos ellos descubriríamos un interés por el paisaje en el proceso de reconversión, y en todos ellos el objetivo sería la revalorización del suelo del entorno y la atracción turística.

En el ámbito rural las transformaciones en la agricultura han favorecido el mismo proceso. El fuerte incremento de la productividad de la tierra y del trabajo crearon un creciente excedente de mano de obra y dividieron el espacio que antes ocupaba la actividad agraria en dos: una parte en la que se mantuvo de manera muy intensiva y otra de tierras marginales que se convirtieron en terrenos improductivos y que se vieron sometidos a un proceso de progresivo abandono y asilvestramiento. Esta diferenciación se vio además acelerada -sobre todo en la Unión Europea pero también fuera de ella- por las políticas agrarias y de desarrollo rural, las primeras dirigidas aún hacia el productivismo, las segundas hacia la valorización territorial en la que con frecuencia se han establecido objetivos paisajísticos o se ha utilizado el paisaje como atracción turística.

Entre los estudiosos y profesionales que vienen hoy ocupándose del paisaje, el enfoque de los economistas resulta realmente esclarecedor para reconocer el verdadero papel que juega hoy éste. En 1999 una publicación de la Organización para la Cooperación y el Desarrollo Económicos [OCDE] proporciona muchas pistas al respecto. En realidad esta publicación no trata exactamente del paisaje, sino de lo que denomina "amenidades" rurales y que define como:

una amplia gama de estructuras únicas, naturales o construidas por el hombre en zona rural, tales como la flora y la fauna, los paisajes cultivados, el patrimonio histórico o las tradiciones culturales... que se distinguen de las características más ordinarias del campo porque son reconocidas como preciosas o, en términos económicos, explotables. Se trataría, por tanto, de lugares y tradiciones de los cuales ciertos individuos, o la sociedad en su conjunto, pueden obtener una utilidad (entendida, claro está, en forma de beneficio económico) (OCDE, 1999, p. 7).

El paisaje, por tanto, formaría parte de estas amenidades y tendría por objeto la obtención de una utilidad económica.

Ahora bien, ¿de qué manera proporciona el paisaje esa utilidad económica? ¿Es acaso el paisaje una mercancía? Evidentemente no. Que el paisaje se haya mercantilizado no significa que podamos considerarlo una mercancía en sí. Primero porque en muchos casos los elementos subyacentes a la representación paisajística no fueron producidos con el objeto de crear un paisaje bello; unos forman parte de la naturaleza, otros fueron construidos con fines productivos o residenciales. Segundo porque aunque el espacio hubiese sido diseñado con propósitos paisajísticos, hace ya mucho tiempo que los elementos que lo conformaban han quedado subsumidos en su estructura actual. Finalmente, si bien es cierto que los estudios sobre el paisaje (la construcción de la imagen), las iniciativas promocionales y las intervenciones productivas de acondicionamiento, forman parte de su puesta en valor y contribuyen a su mercantilización, no por ello lo convierten directamente en mercancía. Para que fuera así el paisaje debería poder ser privatizado y cumplir las propiedades de rivalidad y exclusión propias de los bienes privados (Husson, 2013). Por el contrario el paisaje aparece más bien como un bien común del que, en principio, podría disfrutar todo el mundo. Claro está que existen vías para su privatización, aunque no generalizables. Facchini (2011) muestra un camino para ello: cuando para contemplar un paisaje sea necesario alcanzar un lugar que lo permita (un punto de visión), su apropiación podría producirse mediante la apropiación de 
esos puntos de visión que permiten contemplarlo. El mercado del paisaje se puede organizar entonces en torno a la compra y venta de esos lugares con vistas. Pero entendido así quizás sea más adecuado considerarlo como una externalidad positiva, es decir, una cualidad cuyo consumo repercute positivamente en el consumo de otro bien -éste sí privado-dando origen a una renta diferencial (Husson, 2013).

Como externalidad positiva su utilidad económica se muestra de tres maneras: incrementando el precio del suelo para la construcción, como reclamo de inversores y consumidores turísticos y proporcionando una identidad a ciertas producciones locales para alcanzar en el mercado precios competitivos. En el primer caso, el papel que el paisaje juega en el mercado inmobiliario es limitado, sobre todo en lo que se refiere a la vivienda principal. Porque en este caso existen otros factores que se tienen más en cuenta, como la distancia y la calidad de los accesos. De ahí el éxito de las áreas periurbanas (de segunda o tercera aureola) en las que los paisajes rurales tienen menos atractivos pero se encuentran más próximas a los centros de trabajo o disponen de rápidos accesos. En las viviendas secundarias esos factores limitadores tienen mucho menos peso y el paisaje juega un papel más destacado en el precio del suelo. Por otra parte, la mejora de las infraestructuras y de las comunicaciones han permitido ampliar la distancia y hacer más accesibles paisajes de mayor calidad (Dissart y Vollet, 2011), aumentando con ello también el peligro de su deterioro. En cualquiera de los casos, los lugares más demandados son los que ofrecen mejor visión y la ordenación del territorio suele ser la vía que favorece la mercantilización y la renta diferencial. Una ordenación que generalmente se muestra "protectora" con el paisaje contemplado y permisiva con los lugares desde los que se puede contemplar, y que, por lo tanto, no suele garantizar la permanencia de las vistas amenazadas por la obstrucción de nuevas construcciones (Facchini, 2011).

La inversión pública en infraestructuras resulta fundamental para la explotación turística del paisaje. La construcción de autopistas, carreteras o incluso pistas permite llegar vehículos a los lugares de contemplación o incluso al corazón de los elementos físicos más destacados del paisaje. La afición de las administraciones regionales y locales por los teleféricos, trenecillos, barquitos, etc., -muchas veces construidos con dinero público y entregados luego en concesión privada-, constituye una buena muestra de cómo se viene organizando la explotación turística del paisaje.

La tercera vía de obtención de beneficio económico a partir del paisaje, la aportación de identidad a producciones locales, depende en gran medida de la promoción y la creación de imagen, en la que también suelen participar muy activamente -aunque no exclusivamente- las administraciones públicas en beneficio de la explotación privada. La singularidad paisajística asociada a la mercancía adquiere así particular relevancia. En ocasiones se asocia también a la tradición y otras amenidades: paisaje y saber hacer tradicional ofrecen garantía de calidad; y a su vez, el consumo de dichos productos garantizan el mantenimiento de los paisajes y del saber artesanal. Y ambas cosas justifican un precio más elevado. Quizás el caso más destacado de aportación de identidad a producciones locales sea el del vino. Los franceses, que lideran el sector vitivinícola europeo, tienen ya gran experiencia en la identificación de sus vinos con los paisajes de viñedo regionales; han peleado judicialmente para preservar sus denominaciones "champan", "borgoña", "chablis" o "sauternes", cuyas especificidades relacionan directamente con el terroir, síntesis de la calidad de la tierra, el clima y la tradición (Harvey, 2011). Y con frecuencia han utilizado imágenes de paisaje en sus anuncios promocionales, caso, por ejemplo, del vino de Rosellón que utilizaba las del viñedo aterrazado de la Côte Vermeille (Galiana, 1996).

\section{LA APUESTA INSTITUCIONAL POR EL PAISAJE: LOS OBJETIVOS PRIORITARIOS EN LA LEGISLACIÓN}

No merece demasiado la pena detenerse en los antecedentes del Convenio Europeo del Paisaje (CEP), bastante indefinidos y más bien orientados a los espacios naturales, al patrimonio histórico monumental o a la ordenación del territorio, a excepción quizás de la Carta del Paisaje Mediterráneo (Askasibar, 1998) y el Landscape Character Assessment, que han incluido decisivamente en la propia definición adoptada en el Convenio.

El documento que daría lugar al CEP comenzó a prepararse en 1994 y fue aprobado definitivamente en Florencia el año 2000. Surgió con vocación de ser un instrumento legal vinculante y consiguió una gran aceptación tanto entre los políticos como entre los técnicos y profesionales, que apenas sugirieron -en tono poco crítico- algunas deficiencias en cuanto a la ambigüedad de la definición. 
En el propio preámbulo deja claro que "el paisaje constituye un recurso favorable para la actividad económica y que su protección, gestión y ordenación pueden contribuir a la creación de empleo". Es verdad que también menciona su importancia cultural, ecológica, medioambiental y social, pero esos aspectos tendrán claramente una importancia secundaria, meramente justificativa, y adoptarán formas ambiguas y contradictorias. El objetivo explícito del Convenio, según se expresa en el artículo 3, es promover la protección, gestión y ordenación de los paisajes, definiendo la protección como la conservación de los aspectos significativos del paisaje por su valor patrimonial, la gestión como el mantenimiento del paisaje frente a las transformaciones y la ordenación como las acciones con vistas a mejorar, restaurar y crear paisajes (Art. 1-Definiciones). Estas últimas acciones previstas forman, a mi modo de ver, parte esencial del verdadero objetivo perseguido.

La definición de paisaje que propone -citada hasta la saciedad- es la de "cualquier parte del territorio tal como la percibe la población, cuyo carácter sea el resultado de la acción y la interacción de factores naturales y/o humanos". La primera parte, la que se refiere a la totalidad del territorio, ha sido muy celebrada por los geógrafos, que han querido ver en ello la superación de la asociación restrictiva de los paisajes con los lugares pintorescos y las bellezas naturales. La definición parece incluir ahora todos los paisajes, tanto naturales como rurales, periurbanos, urbanos e incluso degradados (Zoido, 2000; Askasibar, 1998). $\mathrm{Y}$ es que en realidad, la inclusión de todo el territorio europeo constituye -en mi opinión- una de las claves del verdadero objetivo del Convenio: la utilización del paisaje en la valorización de los territorios. Ningún paisaje es feo, decía Unamuno; hay que saberlo ver. Y para ello es necesario construir una imagen atractiva más allá de las características formales del espacio e intervenir sobre el territorio mismo para crear "paisajes mejorados".

Algunos especialistas han llamado la atención sobre una supuesta doble consideración del paisaje en la definición, una doble dimensión objetiva y subjetiva, tangible e intangible a la vez. Sin embargo, a mi entender, el paisaje del CEP es enteramente subjetivo, puesto que es -como se hace explícito- la percepción que las poblaciones tienen del territorio. Cada territorio cuenta con su paisaje, pero éste sólo se revela a partir de la percepción de las poblaciones. Y, por cierto, como dicen algunos economistas, esa referencia a las poblaciones resulta clave para su interés profesional, en tanto que les permite determinar la demanda paisajística, aunque ésta no sea observable en el mercado (Lifran, Rambonilaza y Westerberg, 2008). El problema se planteará precisamente en cómo objetivar el paisaje, en cómo construir una imagen de paisaje que resulte atractiva al conjunto (o al menos a la mayor parte) de las poblaciones, en cómo moldear el gusto e incluso manipular la sensibilidad de las poblaciones.

En cuanto a la atribución causal incluida en la definición, "la interacción de factores naturales y/o humanos" proporciona -según el texto- "el carácter del paisaje". En una versión anterior, que llegó a ser aprobada por el Congreso de Administraciones Locales y Regionales de Europa en 1998, la definición era algo distinta y el lugar del término "carácter" era ocupado por el de "aspecto"3. Florencio Zoido, que valoraba esta primera versión en un artículo del año 2000, destacaba este último término por su referencia concreta a la forma, que lo aproximaba a la noción más tradicional de la Geografía del paisaje. Y ciertamente, el término "aspecto" nos remite más claramente a la idea de apariencia, de fisonomía, de semblante. Por el contrario, el término "carácter" es bastante más ambiguo, de significado más incierto ya que remite a cualidades tanto visibles como invisibles. Refleja, sin duda, la influencia británica, la asunción de la noción de "landscape character" que desde mediados de los años ochenta sirvió en el Reino Unido para definir sus paisajes. Se trataba de una herramienta construida para identificar los elementos que hacen singular a un paisaje y dan sentido de lugar a un área (Swanwick, 2002). Y lo que aquí importa es que la incorporación del término "carácter" resulta más útil al verdadero objetivo del Convenio, ya que permite añadir nuevos elementos de valoración al paisaje, relacionados, por ejemplo, con las identidades, las conmemoraciones, las sensaciones y las emociones. Es decir, cuando se refiere a "la interacción de factores naturales y/o humanos", los factores humanos podrían no ser propiamente físicos (técnicas de acondicionamiento, de cultivo, diseño de construcción, etc.), sino también simbólicos, sensitivos, emotivos o sensibles.

Territorio y paisaje quedan, por tanto, bien diferenciados en el texto. El territorio resulta imprescindible porque, en definitiva, es la dimensión física, real y tangible, sobre la que hay que actuar. Como dice

3 La definición era: "una porción de territorio, pudiendo incluir las aguas costeras y/o interiores, tal como es percibida por las poblaciones y cuyo aspecto resulta de la acción de factores naturales y humanos y de sus interrelaciones". 
Martínez de Pisón (2000), el territorio "permite introducir en él (en el paisaje) hechos geográficos controlables, como constituyentes materiales, espacialidad, escala, unidades y comarcalización, además de sus significados culturales" (p. 15). Hechos geográficos sobre los que intervenir para construir los nuevos paisajes destinados a valorizar el espacio, sobre los que aplicar políticas territoriales favorecedoras de la conservación y construcción del paisaje y también de la explotación del mismo como recurso (Dissart y Vollet, 2011). Pero también se puede y se debe (según se deduce del discurso dominante) actuar sobre la representación, es decir, sobre el paisaje mismo, construyendo una imagen más o menos bella y connotándola con otros elementos valorativos identitarios, resaltando sus cualidades ambientales, los retazos de su historia que dejaron huella y marcaron su carácter (del paisaje y del paisanaje), las costumbres tradicionales que expresan las relaciones de la población con su entorno; incorporando las evocaciones sensitivas (olores, sabores, sonidos) y las miradas cultas de la literatura y la pintura. En definitiva, construir una imagen identitaria, reveladora del carácter singular del paisaje y de su riqueza y diversidad.

\subsection{La construcción fundamentada de imágenes pasajísticas: identificación, selección y valoración de los paisajes.}

Las imágenes se crean primero en el propio proceso de identificación y valoración de los paisajes, que constituye uno de los compromisos recogido en el artículo 6 del Convenio. En realidad ese proceso es lo que venimos entendiendo como "patrimonialización". Porque una vez identificados y valorados los paisajes heredados del pasado, una vez seleccionados y calificados (es decir, apropiados), se convierten en imágenes que, en la medida de lo posible, deberían ser preservadas en lo esencial (de su carácter) para las generaciones futuras. En ese proceso de patrimonialización intervienen al menos dos orientaciones que se retroalimentan mutuamente: una que se ocupa de la fundamentación de los paisajes a partir del análisis y la valoración, y la otra que se dirige a la promoción de un espacio concreto o de una producción concreta a partir del paisaje.

¿Cómo identificar y valorar los paisajes en el sentido propuesto en el CEP? Evidentemente se trata de un trabajo de expertos (una oportunidad para los geógrafos como así lo vienen entendiendo). El Convenio recoge incluso la necesidad de que las partes (los países firmantes) acepten formar especialistas e introduzcan programas y cursos orientados en ese sentido.

Después del análisis y la selección se entra en los aspectos valorativos, que resultan ser los más complicados aunque, evidentemente, es la parte más importante en la formación de un paisaje competitivo. Y serán también expertos (de diferentes disciplinas) los encargados de la construcción de la imagen. Ahora bien, conscientes de que la valoración tiene una parte de subjetividad importante -la relacionada con la percepción- tratan de recurrir -como prevé el propio Convenio- a la participación de la población. Pero ¿de qué "población", de la que vive en ese territorio, de la que lo visita con mayor o menor frecuencia, de la que pudiera visitarlo y que sólo lo conoce a través de imágenes promocionales? Ciertamente, el paisaje es o debería ser un bien común a disposición de cualquiera que desee disfrutarlo. ¿Pero quiénes son competentes para valorar un determinado paisaje? ¿A quiénes deben dirigirse los expertos para recabar la valoración de la población? Swanwick (2002) se decide por un segmento de la población que no sólo puede participar en la valoración del paisaje sino también involucrarse en los procesos de gestión, conservación y recreación, al que denomina "stakeholder", que podríamos traducir como "quien apuesta por el paisaje". Una apuesta sostenida por diferentes intereses materiales, como los de los propietarios de la tierra o los residentes, pero también subjetivos, que tienen que ver con sus relaciones íntimas y sensibles con el territorio o con el gusto estético. En nuestro país algunos trabajos recientes parecen haber tomado esa misma opción, aunque considerándola tan sólo como una parte -eso sí cualificada- de la valoración, que debería ser complementada "con la percepción del conjunto de la sociedad" (Mata Olmo y Fernández Muñoz, 2013, p. 79). ¿Pero acaso existe una percepción social anterior a la creación de la imagen? ¿Quién la representaría?

Hasta hace poco la población residente rural era incapaz de ver su paisaje. Recordemos a aquel pastor convertido en guía ocasional de José Macpherson, que aturdido ante los elogios que el geólogo dedicaba al paisaje del desnudo roquedo de la sierra acabó por decirle: Don José, ¿cómo se asombra usted tanto de eso, si no es na? (Ortega Cantero, 1986). Roger (2007) cita también al respecto la investigación realizada a mediados de los años ochenta del siglo pasado por Martín de Soudière con los campesinos de Margeride sobre su percepción del paisaje del territorio que habitaban, llegando a la conclusión de que ni siquiera 
entendían el término en toda su dimensión, identificando lo bello y lo útil, la belleza de un prado con su capacidad productiva. Si hoy muchos habitantes del medio rural pueden ver el paisaje es en buena medida debido a una mayor educación (que también incluye la formación del gusto) y a las imágenes que desde el exterior se han ido construyendo del territorio en que viven o de otros muy similares. Es verdad que, sin reconocerlo como paisaje, la mayor parte de las poblaciones locales han otorgado siempre valores simbólicos a algunos elementos visuales de su territorio, y también es verdad que tales elementos contribuyen a formar su identidad en la medida en que refuerzan su identificación con el territorio. Pero esas comunidades no viven en el paisaje (donde, por otra parte, no puede vivir nadie), viven en un territorio construido a lo largo de generaciones y que constituye su verdadero patrimonio. Sólo hace unas décadas descubrieron que las poblaciones urbanas contemplaban con agrado el aspecto de sus campos, de sus pueblos, de sus bosques, de sus montes, de la misma manera que valoraban algunos elementos en desuso de su economía tradicional, como los silos, los potros de herrar o las cabañas de pastor; y se sorprendieron igual que el guía de Macpherson, pero pronto buena parte de ellos decidieron jugar a ese nuevo juego, porque en definitiva enseguida comprendieron que ese paisaje admirado se estaba construyendo sobre su territorio y que ello tenía consecuencias sobre la valorización de su patrimonio, en parte devaluado por la crisis de las actividades agropecuarias. Si eran propietarios de las tierras y las casas esa demanda de paisaje suponía -al menos hasta la crisis de 2008- un incremento de su precio que algunos supieron aprovechar. Como autóctonos bien pueden ayudar a los expertos a valorar el paisaje proporcionándoles información sobre los valores identitarios, tan fundamentales en la construcción de una singularidad paisajísitica competitiva. Pero no olvidemos que no siempre estarán de acuerdo con ciertas restricciones normativas que puedan limitar su beneficio a favor del mantenimiento del paisaje, de su estética o de su tradicionalidad. Su papel como "stakeholder" resulta en este sentido contradictorio, pero no más que el del constructor para quien el paisaje constituye una oportunidad, o que el de la administración local o el agente de desarrollo rural interesados también sobre todo en los réditos económicos y políticos que éste pueda proporcionar.

Por otro lado, la población no residente que usa o podría usar el espacio de modo más o menos ocasional, constituye la potencial demanda y tiene que jugar un papel importante en las entrevistas de los expertos. Pero las dificultades metodológicas resultan evidentes. Comienzan con la selección misma de la muestra y continúan por el propio sistema de transferencia y tratamiento de la información. Algunos prefieren utilizar métodos cuantitativos consistentes en pedir a diferentes personas (no profesionales) que establezcan relaciones entre distintos elementos del paisaje y señalen sus preferencias (Lifran, Rambonilaza y Westerberg, 2008). Otros optan por métodos mixtos cuantitativos-cualitativos, realizando entrevistas en profundidad e incluso talleres de participación (Mata Olmo y Fernández Muñoz, 2013). Lo más interesante en cualquier caso es que la información funciona en ambos sentidos, de los informantes a los expertos transmitiéndoles sus preferencias y de los expertos a los informantes contribuyendo a descubrirles una imagen que se encuentra ya casi formada.

Algunos especialistas consideran que son sólo los expertos, desde sus respectivas disciplinas y a través de una suerte de hermenéutica, quienes pueden enseñar a leer, admirar y saborear los paisajes. Según Ojeda (2013) éstos actuarían: "como mediadores o exégetas, partiendo de la siguiente interrogante: ¿Cómo podemos inducir unos reconocimientos, disfrutes, comprensiones y valoraciones de los paisajes, tales que susciten o subrayen el aprecio social y el compromiso ético con los mismos?" (p. 38). Los discursos disciplinares acabarán confluyendo en una discurso común, orientador de las "miradas y las atenciones hacia paisajes, temas y lugares concretos y significativos" (p. 60).

En este sentido, los expertos serían los verdaderos "artealizadores" del territorio, los transformadores del país en paisaje, según la formulación de Roger (2007), y también, por tanto, los promotores de la patrimonialización del paisaje. Y en parte así es. Con o sin la ayuda de las poblaciones ya mediatizadas, los diferentes expertos en paisaje juegan un papel fundamental como constructores de los mismos a partir de sus discursos, como creadores de la imagen, de la representación connotada del territorio. Los artistas (escritores, pintores, fotógrafos, cineastas) también contribuyen decisivamente en esa construcción, y juegan un papel aún más destacado en la difusión y promoción de los mismos.

¿Qué cualidades debe tener el paisaje para ser apreciado, para ofrecer una valorización competitiva del territorio?

La imagen construida debe ser en primer lugar atractiva. El hecho de que se consideren en el CEP todos los paisajes no es contradictorio con este principio. Hay que convertir en atractivos incluso los 
paisajes feos, bien sea cambiándolos bien interviniendo sobre el gusto a través de la connotación. Recordemos de nuevo el papel jugado por algunos escritores españoles de la generación del 98 -principalmente Unamuno, Azorín o Machado- en el embellecimiento de la árida y monótona Castilla. O la aportación de numerosos fotógrafos cuyos objetivos han reconstruido muchos paisajes generando y difundiendo nuevas imágenes de la imagen (es decir del paisaje). Ya sabemos que las cámaras no siempre dicen la verdad. Decía Lewis Hine que aunque las fotos no mienten, los mentirosos pueden hacer fotos (Burke, 2005). Su veracidad depende por tanto de la intervención del "desalmado fotógrafo" empeñado en crear (Benjamin, 2008). La selección del encuadre, de los elementos a incluir, la altura del horizonte, la estación del año, la luz... son intervenciones nada inocentes, destinadas a conseguir el efecto perseguido. Para Enrique Carbó (fotógrafo plástico y conceptual) la fotografía es, precisamente, "la posibilidad de transformar cualquier territorio en paisaje" (Saule-Sorbé, 2006, p. 93). En realidad las fotografías promocionales turísticas no hacen otra cosa. Pero también lo consiguen algunas realizadas con criterios artísticos si llegan a tener una difusión suficiente. Carbó, por ejemplo, dedicó una serie de fotografías a las relativamente recientes torres del agua de Béarn y consiguió integrarlas en un paisaje histórico al que en un principio parecían romper. Muchos otros ejemplos podrían ponerse del papel que las cámaras han jugado en la aceptación y reconocimiento de la obra pública como parte del paisaje. ¿Servirán en el futuro para integrar los polémicos aerogeneradores o los campos de paneles solares? Es probable; de hecho ya lo vienen haciendo, aunque en todo caso estos nuevos elementos cuentan con otros aliados como la connotación ecológica, la fuerza de expresar una alternativa energética (Nadaii, 2011).

En efecto, valorar el paisaje ecológicamente constituye otra de las formas de hacerlo atractivo. No hay que recordar de nuevo que los paisajes referidos a espacios que conservan una alta naturalidad -lo que solemos llamar paisajes naturales- son siempre bien valorados, sobre todo si corresponden a áreas de montaña. La evaluación ambiental y ecológica forma parte de todos los planes paisajísticos y se aplica a todos los espacios convertidos en paisaje. Lo que habría que preguntarse es si unas buenas condiciones ecológicas del espacio geográfico se traducen siempre en un paisaje atractivo y, sobre todo, viceversa. La relación entre el concepto medio ambiente y la noción de paisaje depende, en principio, de cómo se defina "paisaje". Cuando éste incluye la realidad física representada -tal y como hacen buena parte de los geógrafos en la actualidad- esa relación es de integración plena: el paisaje forma parte del medio ambiente, aunque algunos autores que participan de esta idea insisten en reclamar una atención independiente de la que se dedica al "impacto ambiental" para el "impacto paisajístico" (Martínez de Pisón, 2009). Por el contrario, para aquellos que piensan que el paisaje no es más que una representación, la relación se expresa en sentido inverso: el paisaje puede aparecer connotado con matices ambientalistas o ecológicos, es decir tintado por lo que Roger (2007) llama "verdolatría", pero en absoluto forma parte del medio ambiente, que es un concepto científico referido exclusivamente a la realidad física.

Además de atractiva la imagen debe ser singular, esto es, estar dotada de señas de identidad propias, de personalidad, de "carácter". Ello es lo que convierte al espacio o al territorio de referencia en más o menos competitivo. La OCDE (1999), en el texto citado sobre las amenidades rurales, insiste sobre este aspecto. Las propias formas de ese espacio son ya, por supuesto, singulares e irrepetibles, pero necesitan de un discurso que resalte sus particularidades, que refuerce sus identidades, que ordene la mirada y justifique su autenticidad. Porque, como en el caso de la obra de arte, debe tratarse de un paisaje único y auténtico. Y la historia es parte indispensable de ese discurso autentificador del paisaje, que es en sí un testimonio histórico (Benjamin, 2008). Contribuye, por un lado, a proporcionarle antigüedad, espesor, y, por otro, a explicar las características de la singular organización física del espacio que representa. En este sentido la historia ha sido parte consustancial de todo proceso de patrimonialización incluso desde antes de que se pensase en paisajes patrimoniales. Se trata, en todo caso, de un discurso histórico selectivo. Basta con una explicación histórica que fundamente lo esencial de la imagen, que la ilumine, enriquezca y de cuenta de su autenticidad. No tiene sentido una historia crítica ni social del territorio.

Junto con la historia, como parte de ella, la conservación de la tradicionalidad constituye otra de las claves que refuerzan la autenticidad. Los paisajes culturales rurales expresan las prácticas de producción, de organización del espacio y los modos de vida de sus habitantes. Entendidos así, los paisajes culturales auténticos tienen mucho de etnográficos y estos elementos son muy cuidados en las imágenes construidas en los planes de paisaje. Ciertamente resulta complicado incluso en el nivel del discurso que construye la imagen, mantener una tradicionalidad estática, un paisaje congelado en el tiempo. Es inevitable asumir cierta evolución, cambios que no destruyan lo esencial de lo autóctono, identificado por algunos autores 
(Besse, 2003 y Gómez Mendoza, 2013) con lo genuino o lo vernáculo que incorporó Jackson (2010). Pero en realidad para Jackson los elementos vernaculares del paisaje, en contraposición con los políticos (que vendrían a ser los diseñados y construidos por las instituciones del poder), identificarían el paisaje vivido que evoluciona involuntariamente adaptándose a las circunstancia. Sus elementos constantes serían en buena parte inmateriales e invisibles: ritos, canciones, costumbres, olores...; esencias propias de los "lugares" definidos por la fenomenología, que mantienen el carácter de la comunidad que los habita y que como tal reconoce su espacio más allá de los cambios en los usos del suelo, en la forma de las viviendas, de los caminos, incluso de los introducidos por las instituciones políticas. Lo autóctono, para Jackson, se encuentra en la comunidad y es ésta la que lo transfiere al paisaje vernáculo. Resulta, por tanto, difícil de reconocer por los de fuera y será por ello necesario incorporarlo a la imagen. Paisaje y paisanaje se funden así en la representación que reciben los visitantes, que acabarán considerando a los campesinos como una parte más de ese paisaje (Burke, 2005). La desaparición de los campesinos también tendrá que ser suplida por reconstrucciones más o menos afortunadas de la tradicionalidad, reforzando la imagen, por ejemplo, con matices enogastronómicos que busquen sus raíces en las producciones locales tradicionales.

Hoy esos paisajes construidos o en construcción se difunden e imponen a velocidad vertiginosa. Vivimos en la era de la imagen. Las fotografías o películas promocionales inducen y condicionan la percepción común hasta convertirse, como dice Vecchio (2009), en auténticos "a priori kantianos". Visualización inducida lo denomina Nogué (2007), que reconoce que hoy los paisajes contemplados que tienen éxito son aquellos cuyas imágenes han sido previamente difundidas por la televisión, los suplementos de periódicos, las revistas de viajes o las fotografías de los turoperadores. Un fenómeno no enteramente nuevo, ya que desde hace mucho tiempo las guías turísticas, cuando proporcionan información paisajística, suelen ser muy dirigistas: indican los mejores lugares de contemplación, lo que debe verse, lo que debe pensarse e incluso lo que debe sentirse (Laplace, 2007).

\subsection{De la imagen a la realidad: el paisaje y la ordenación del territorio}

Pero valorar no es lo mismo que valorizar ${ }^{4}$, y esto último es, a mi entender, el principal objetivo. Por eso, a partir de la imagen -o sin contar con ella más que como reclamo- hay que intervenir en el territorio, abriendo frecuentemente un proceso profundamente contradictorio.

Recordemos de nuevo que el artículo $3^{\circ}$ del CEP establece como objetivo "promover la protección, gestión y ordenación de los paisajes". Pero ¿qué hay que proteger, gestionar y ordenar? Inicialmente la respuesta a esa pregunta podría ser: hacer que la realidad se aproxime lo más posible a la imagen. En el terreno del urbanismo y del paisaje urbano existe ya una larga experiencia al respecto. El diseño de proyectos -que se ajustan a la reglamentación previa y recogen las aspiraciones de diversos actores públicos y privados- permite llevar a la realidad con bastante fidelidad la imagen construida, en parte porque ésta se construye en el propio proyecto (Oueslati, Salanié et Garnier, 2011). Pero en el medio rural la cuestión es distinta. Primero porque cambia la escala, segundo porque los elementos del paisaje tienen un componente natural importante -a pesar de su antropización-y tercero porque si en el medio urbano la función residencial es totalmente dominante, en el rural ésta es secundaria en lo que hace a la superficie que ocupa y al papel que juega en el paisaje, dominando los espacios agrícolas, ganaderos o forestales, o el roquedo desnudo en algunos paisajes de montaña. Por eso, para la mayoría de esos espacios la intervención debería responder más a un plan de conservación que de construcción; de conservación de los "aspectos significativos o característicos" (art. $1^{\circ} \mathrm{d}$ del CEP) que se incluían en la imagen creada. ¿Pero qué aspectos? Tampoco eso resulta fácil. Cuando a los economistas se les encarga la evaluación económica de un proyecto de conservación o modificación del paisaje suelen exigir que éstos sean expresados por un número limitado de atributos entre los cuales se puedan seleccionar aquellos bien definidos por la demanda, a veces sólo uno, otras varios que se complementan formando un "efecto composición", es decir, una escena valorada por el consumidor (Lifran, Rambonilaza y Westerberg, 2011).

En todo caso, la mera conservación o gestión de lo que existe es casi siempre excepcional; lo más frecuente es la intervención física, dado que ella misma constituye una forma de obtener beneficio. Pre-

\footnotetext{
4 En realizar en el DRAE se utilizan como sinónimos, pero aquí se ha venido introduciendo un matiz diferenciador. La valoración se ha utilizado en términos generales, relacionados más con la estética y la calidad, mientras se ha reservado el término de valorización para evocar el aumento de valor económico o la posibilidad de obtención de beneficios y rentas diferenciales.
} 
domina "la ordenación" tal y como la define el CEP, es decir, las intervenciones de mejora, restauración y creación de paisaje. Pequeñas o grandes obras destinadas a regenerar el paisaje (plantación de árboles, acondicionamiento de riberas, restauración de canteras, etc.), a facilitar el acceso, la contemplación o la información: antiguos espacios mineros o industriales convertidos en jardines, sendas que se cubren de hormigón y se llenan de pasarelas, puntos de visibilidad convertidos en miradores construidos, siembra de cartelería indicativa y explicativa, centros de interpretación; a veces obras más agresivas, como nuevos viales, trenecillos o funiculares; o más privativas, como campos de golf. Intervenciones que pretenden volver el paisaje más visible, más penetrable, más "civilizado", más atractivo, y que constituyen verdaderos planes de gentrificación, si se me permite extender al territorio en general esta denominación de una práctica genuinamente urbana y destinada a revalorizar el suelo y la vivienda de ciertos barrios urbanos degradados. Intervenciones que en sí mismas constituyen ya transferencia de fondos públicos a la iniciativa privada a través de la propia construcción, mantenimiento y gestión de las infraestructuras. No puede extrañarnos que en estas intervenciones -sobre todo en las más puntuales- jueguen un papel destacado (o lo han jugado antes de la crisis y esperan volver a hacerlo en el futuro) las administraciones locales, pues es a esa escala donde la gentrificación tiene más sentido. Por eso, los programas de desarrollo rural o local, a través de sus asociaciones y destinando a ello también mayoritariamente dinero público (de las administraciones autonómicas, locales y europeas), han venido constituyendo una de las fórmulas más ampliamente utilizadas.

\section{CONCLUSIÓN}

Existe un fuerte componente neorromántico en la mayor parte de especialistas que tratan hoy del paisaje. Interpretan la recuperación del interés por el mismo como un cambio en la orientación del ser humano hacia planteamientos más éticos y respetuosos con el medio ambiente y el propio paisaje. Para Berque (2009) ello supone una ruptura con la modernidad, con la práctica habitual que engendra fealdad y obliga a que nos ocupemos de preservar el paisaje. Pero es imposible cerrar los ojos ante los desastres que se han producido en los tres últimos lustros. Ha sido precisamente en estos años en los que el paisaje cobraba relevancia pluridisciplinar y política, en los que se ha acelerado el deterioro de los propios valores que se le otorgan. En España, una imagen que puede sintetizar esta época de los horrores tan adornada por la literatura sobre el paisaje, es la proporcionada por el libro de Julia Schulz-Dornburg (2012) titulado Ruinas Modernas: una topografía de lucro, que recoge, a modo de inventario fotográfico, la construcción especulativa abandonada en España.

Todo lleva a pensar, por tanto, que el interés de las últimas décadas por el paisaje procede de una estrategia de valorización económica del territorio de orientación capitalista e impulsada decididamente por las administraciones públicas a todas las escalas. Quienes consideren que las inversiones que el paisaje pueda atraer al medio rural son pequeñas (pequeños alojamientos, algunas viviendas secundarias, etc.) y no pueden haber generado ninguna estrategia de acumulación, pasan por alto que buena parte de ese capital procede de entidades financieras y que es allí donde se concentra el beneficio, en lo que se ha dado en llamar "circuito secundario de acumulación" (Harvey, 2007; López y Rodríguez, 2010). El propio aumento del valor del suelo al pasar de rural a urbano supone ya un suculento cebo para capitales especulativos. También olvidan el incremento conseguido en las ventas de vehículos todoterreno, en cuya propaganda -"llega donde nadie puede" - se ofrece una ventaja de exclusividad para disfrutar cómodamente de paisajes de dificultosa accesibilidad. Y no olvidemos el propio beneficio obtenido en las obras de acondicionamiento, mejora y creación del paisaje y los convenios público-privados firmados para ello, que constituyen una manera muy importante de transferir fondos públicos a la empresa privada.

Una vez, hablando con un pequeño propietario rural de un municipio próximo a la costa de Cantabria, me contaba que cuando la presión urbanística llegó al pueblo se resistió a vender sus tierras, que aunque ya no utilizaba como explotación agraria servían de desahogo a su casa y le hacían creer que aún vivía en el campo. Un día, sin embargo, lo vio todo claro y reunió a su familia para comunicarles su plan. He decidido vender, les dijo. El pueblo está alcanzando una densidad de edificaciones tan alta que dentro de poco apenas quedará espacio, y aquellos que vinieron atraídos por el paisaje y la calidad ambiental pedirán un parque, un espacio de desahogo. Entonces mirarán nuestras fincas y presionarán al ayuntamiento para que las expropie y construya el parque. Las perderemos a un precio mucho más bajo del que hoy podemos conseguir. 
Así funcionan realmente las cosas. En el proceso global de urbanización social y física (Lefebvre, 1972), acelerado a un ritmo vertiginoso en los últimos tiempos, el paisaje se integra en forma de retazos más o menos extensos y "artelizados", y cumple en el espacio un papel similar al de la gentrificación urbana. El paisaje constituye el atractivo que incorpora valor al territorio, que permite el desarrollo de actividades turísticas, que valoriza el suelo e incentiva la construcción, que ameniza las actividades de ocio, que añade valor a las producciones locales. Pero con frecuencia esas prácticas acaban por deteriorar la imagen vendida. La legislación sobre el paisaje pretende "guiar y armonizar" esas transformaciones, pero no deteniéndolas sino diseñando un nuevo paisaje, construyendo un nuevo jardín, no precisamente del Eden pero sí suficientemente atractivo como para contentar a los decepcionados por tanto asfalto y cemento.

Y así lo ha entendido el Convenio Europeo del Paisaje, por más que un cierto fetichismo discursivo pretenda desviar nuestra atención hacia otros aspectos de apariencia más ética, incluso regeneradora en tanto que conservadora de la belleza paisajística y de valores ambientales que mejoran la calidad de vida. La cuestión es para quién. Los nuevos espacios gentrificados ofrecen, desde luego una buena calidad de vida para quien pueda pagarlos o incluso visitarlos. No olvidemos, por otra parte, que en muchos casos la restauración paisajística se produce sobre espacios de reconversión de actividades (industriales, mineros, incluso agrícolas) que conllevan abandono y empobrecimiento de las poblaciones locales (igual que en el caso de la gentrificación urbana). Con frecuencia la terciarización, la explotación turística del espacio que aprovecha el potencial paisajístico, se ofrece como solución alternativa a las actividades perdidas. Pero pocas veces compensan la capacidad de empleo de aquellas. Algunos estudios demuestran, por el contrario, la escasa incidencia que la valoración del paisaje local ha tenido sobre el empleo. Es el caso, por ejemplo, de la mancomunidad de Rochechouart (país de la Météorite en el departamento francés de la Haute-Vienne), que tras una serie de acciones destinadas a mantener y crear paisaje apenas consiguieron emplear -incluidos los efectos multiplicadores- a un 2\% de su población activa (Dissart y Vollet, 2011).

En cuanto al medio ambiente, la conservación, restauración o construcción del paisaje, no es ninguna garantía de mantenimiento o mejora de los valores ambientales, como presupone el CEP. Más bien habría que pensar que contribuye negativamente, incentivando la construcción de viales y carreteras de distintos órdenes e incrementando con ello la frecuentación de vehículos de motor y el acceso a lugares frágiles, extendiendo las áreas construidas, aumentando los consumos energéticos y de agua. En definitiva, fomentando un uso imprudente de los recursos nada acorde con el modelo de desarrollo sostenible que pretende tomar como marco.

\section{REFERENCIAS}

Arnaldo, J. (Ant. y Ed.) (1994). Fragmentos para una teoría romántica del arte. Madrid: Tecnos.

Askasibar Bereziartua, M. (1998). Política y normativa del paisaje en Europa. Lurralde, 21, 155-193. Recuperado de http://www.ingeba.org/lurralde/

Benjamin, W. (2008). Sobre la fotografía. Valencia: Pre-Textos.

Berque, A. (2009). El pensamiento paisajero. Madrid: Biblioteca Nueva. Paisaje y Teoría.

Berrizbeitia, A., Hecht, R. y Muñoz, A. (2008). La idea de paisaje en USA: de naturaleza a ciudad. En Mateu Belles, J y M. Nieto Salvatierra (Ed.): Retorno al paisaje. El saber filosófico, cultural y científico del paisaje en España (pp. 243-282). Valencia: Evren. Recuperado de http://evren.es/wp-content/ uploads/2013/01/LIBRO-EVREN_72_Retorno_al_paisaje_Completo.pdf

Besse, J-M. (2003). Le paysage entre le politique et le vernaculaire. Réflexions à partir de John Brinckerhoff Jackson. ARCHES, Association Roumaine des Chercheurs Francophones en Sciences Humainse, 6, 9-27. Recuperado de http://halshs.archives-ouvertes.fr/halshs-00113275

Besse, J-M. (2006). Las cinco puertas del paisaje. Ensayo de una cartografía de las problemáticas paisajeras contemporáneas. En Javier Maderuelo (Dir.): Paisaje y pensamiento (pp. 145-172). Madrid: Abada Editores.

Brenner, R. (2009). La economía de la turbulencia global. Madrid: Akal.

Burke, P. (2005). Visto y no visto. El uso de la imagen como documento histórico. Barcelona: Crítica. 
Casado de Otaola, S. (2010). Naturaleza patria. Ciencia y sentimiento de la naturaleza en la España del regeneracionismo. Madrid: Fundación Jorge Juan-Marcial Pons.

Corbera Millán, M. (2013). Ciencia, naturaleza y paisaje en Alexander von Humboldt. Boletín de la Asociación de Geógrafos Españoles, 64, 37-64. Recuperado de http://www.age-geografia.es/ojs/index. php/bage/article/viewFile/1695/1612

Dissart, J-Ch. et Volet, D. (2011). Le paysage moteur de développement local. En Oueslati, W. (Coord.), Analyses économiques du paysage (89-116). Paris: Éditions Quae.

Facchini, F. (2011). Paysage et théorie du marché. En Oueslati, W. (Coord.), Analyses économiques du paysage (27-48). Paris: Éditions Quae.

Galiana Martín, J. (1996). Actualidad del paisaje en Francia. De la protección a la gestión paisajística del espacio rural. Ería, 39-40, 93-108. Recuperado de http://www.unioviedo.es/reunido/index.php/RCG/ article/view/1217/1136

Giner de los Ríos, F. (1886). Paisaje. La Ilustración Artística, 219-220

Gombrich, E. H. (1990). Historia del Arte. Madrid: Alianza Editorial.

Gómez Mendoza, J. (2013). Del patrimonio paisaje a los paisajes patrimonio. Documents d'Anàlisi Geogràfica, 59/1, 5-20. Recuperado de http://dag.revista.uab.es/article/view/v59-n1-gomez/pdf

Harvey, D. (2007). El nuevo imperialismo. Madrid: Akal.

Harvey, D. (2011). Espacios del capital. Madrid: Akal.

Harvey, D. (2012). El enigma del capital y las crisis del capitalismo. Madrid: Akal.

Hauser, A. (1975). Fundamentos de la sociología del arte. Madrid: Guadarrama.

Husson, M. (2013). El capitalismo en 10 lecciones. Breve curso ilustrado de economía heterodoxa. Madrid: Viento Sur y La Oveja Roja.

Jackson, J. B. (2010). Descubriendo el paisaje autóctono. Madrid: Biblioteca Nueva.

Lacoste, Y. (1977). À quoi sert le paysage? Qu'est-ce un beau paysage?. Hérodote, 7.

Laplace, D. (2007). Le paysage en pratiques. Exemples à travers deux guides touristiques: L'Itinéraire des Pyrénées d'Adolphe Joanne (1862) et le Guide Régional Michelin Pyrénées Côte d'Argent (19341935). Eria, 73-74, 281-290. Recuperado de http://www.unioviedo.es/reunido/index.php/RCG/article/ view/1588/1503

Lefebvre, H. (1972). La revolución urbana. Madrid: Alianza Editorial.

Lifran, R., Rambonilaza, T. y Westerberg, V. (2011). L'évaluation économique de la demande de paysage, en Oueslati, W. (coord.): Analyses économiques du paysage (pp. 49-62). Paris: Éditions Quae.

López, I. y Rodríguez, E. (2010). Fin de ciclo. Financiarización, territorio y sociedad de propietarios en la onda larga del capitalismo hispano (1959-2010). Madrid: Traficantes de Sueños.

Luginbühl, Y. (1989). Le Paysagiste face aux transformations du paysage rural. Idéologies et pratiques. En Seminario sobre el paisaje (pp. 36-43). Sevilla: Junta de Andalucía, Consejería de Obras Públicas y Transporte. Centro de Estudios Territoriales y Urbanos. Casa de Velázquez. Recuperado de http:// infodigital.opandalucia.es/bvial/bitstream/10326/897/2/897.pdf

Luginbühl, Y. (1991). Le paysage rural. La couleur de l'agricole, la saveur de l'agricole, mais que reste-t-il de l'agricole. Etudes Rurales, 121-124, 27-44.

Maderuelo, J. (2005). El paisaje. Génesis de un concepto. Madrid: Abada Editores.

Marchán Fiz, S. (2006). La experiencia estética de la naturaleza y la construcción del paisaje. En J. Maderuelo (Dir.), Paisaje y pensamiento (pp. 11-54). Madrid: Abada Editores.

Martínez de Pisón, E. (2000). Imagen de la naturaleza de las montañas. En Martínez de Pisón, E. (Dir.), Estudios sobre el paisaje (15-54). Madrid: Universidad Autónoma de Madrid/Fundación Duques de Soria.

Martínez de Pisón, E. (2009). Miradas sobre el paisaje. Madrid: Biblioteca Nueva.

Marx, K. (1979). El Capital. Vol. III. México: Fondo de Cultura Económica. 
Mata Olmo, R. y Fernández Muñoz, S. (2013). Políticas de paisaje y metodologías de análisis y valoración paisajística. En Meer Lecha, A. y Puente Fernández, L. de (Coords), El paisaje en la ordenación del territorio y el planeamiento urbanístico en Cantabria (23-81). Santander: Fundación Botín.

Nadai, A. (2011). Politique de l'énergie et paysages éoliens. En Oueslati, W. (Coord.), Analyses économiques du paysage (189-206). Paris: Éditions Quae.

Nieto Salvatierra, M. (2008). Paisaje del hombre. Espacio, tiempo y estructura. En Mateu Bellés, J y M. Nieto Salvatierra (Ed.), Retorno al paisaje. El saber filosófico, cultural y científico del paisaje en España (9-20). Valencia: Evren. Recuperado de http://evren.es/wp-content/uploads/2013/01/LIBROEVREN_72_Retorno_al_paisaje_Completo.pdf

Nogué, J.(2007). Territorio sin discurso, paisaje sin imaginario. Retos y dilemas. Ería, 73-74, 373-382. Recuperado de http://www.unioviedo.es/reunido/index.php/RCG/article/view/1593/15038

Ojeda Rivera, J. F. (2013). Lectura transdisciplinar de paisajes cotidianos, hacia una valoración patrimonial. Método de aproximación. Revista INVI, 78, 27-75. Recuperado de http://revistainvi.uchile.cl/index. php/INVI/article/view/803/1095

Organización para la Cooperación y el Desarrollo Económicos [OCDE] (1999). Cultiver les aménités rurales. Une perspective de développement économique. Doi: http://dx.doi.org/10.1787/9789264273948-fr

Ortas Durán, E. (1999). Viajeros ante el paisaje aragonés (1759-1850). Zaragoza: Institución Fernando el Católico (CSIC).

Ortega Cantero, N. (1986). La Institución Libre de Enseñanza y el entendimiento del paisaje madrileño. Anales de Geografía de la Universidad Complutense, 6, 81-98. Recuperado de http://revistas.ucm.es/ index.php/AGUC/article/view/AGUC8686110081A/32068

Oueslati, W. (Coord.) (2011). Analyses économiques du paysage. Paris: Éditions Quae.

Roger, A. (2007). Breve tratado del paisaje. Madrid: Biblioteca Nueva.

Saule-Sorbé, H. (2006). Ante la prueba del motivo artístico: algunas reflexiones sobre la observación en el arte del paisaje. En Ortega Canero, N. (Ed.), Imágenes del paisaje (49-101). Madrid: Universidad Autónoma de Madrid y Fundación Duque de Soria.

Schulz-Dornburg, J. (2012). Ruinas Modernas: una topografía de lucro. Barcelona: Àmbit.

Swanwick, C. (2002). Landscape Character Assessment. Guidance for England and Scotland. The Countryside Agency \& Scottish Natural Heritage. Retrieved from http://www.catpaisatge.net/fitxers/ docs/metodologies/LCA_Guidance for_England_and_Scotland.pdf

Vecchio, B. (2009). Geografía de Italia y objetivo fotográfico. Consideraciones al margen de una experiencia editorial. En Copeta, C. y Lois, R. (Eds.), Geografía, paisaje e identidad (51-102). Madrid: Biblioteca Nueva.

Zoido, F. (2000). Líneas en la protección del paisaje. En Martínez de Pisón, E. (Dir.), Estudios sobre el paisaje (293-312). Madrid: Universidad Autónoma de Madrid/Fundación Duques de Soria. 